\title{
Reduction in downstream test utilization following introduction of coronary computed tomography in a cardiology practice
}

\author{
Ronald P. Karlsberg • Matthew J. Budoff • \\ Louise E. J. Thomson • John D. Friedman • \\ Daniel S. Berman
}

Received: 25 August 2009/Accepted: 18 November 2009/Published online: 5 December 2009

(C) The Author(s) 2009. This article is published with open access at Springerlink.com

\begin{abstract}
To compare utilization of non-invasive ischemic testing, invasive coronary angiography (ICA), and percutaneous coronary intervention (PCI) procedures before and after introduction of 64-slice multi-detector row coronary computed tomographic angiography (CCTA) in a large urban primary and consultative cardiology practice. We utilized a review of electronic medical records $\left(\right.$ NotesMD ${ }^{\circledR}$ ) and the electronic practice management system (Megawest ${ }^{\circledR}$ ) encompassing a 4-year period from 2004 to 2007 to determine the number of exercise treadmill (TME), supine bicycle exercise echocardiography (SBE), single photon emission computed tomography (SPECT) myocardial perfusion stress imaging (MPI),
\end{abstract}

R. P. Karlsberg

Cardiovascular Research Foundation of Southern

California, Beverly Hills, CA, USA

M. J. Budoff

Harbor-UCLA Los Angeles Biomedical Research Institute, Torrance, CA, USA

L. E. J. Thomson · J. D. Friedman · D. S. Berman Departments of Imaging and Medicine, Division of Cardiology, Cedars Sinai Medical Center, Los Angeles, CA, USA

R. P. Karlsberg $(\square)$

Clinical Professor of Medicine, David Geffen School of Medicine UCLA, 414 North Camden Drive, Suite 1100, Beverly Hills, CA 90210, USA

e-mail: karlsberg@cvmg.com

URL: http://www.cvmg.com coronary calcium score (CCS), CCTA, ICA, and PCI procedures performed annually. Test utilization in the 2 years prior to and 2 years following availability of CCTA were compared. Over the 4-year period reviewed, the annual utilization of ICA decreased $45 \%(2,083$ procedures in 2004 vs. 1,150 procedures in 2007, $P<0.01)$ and the percentage of ICA cases requiring PCI increased (19\% in 2004 vs. $28 \%$ in 2007, $P<0.001)$. SPECT MPI decreased $19 \%(3,223$ in 2004 vs. 2,614 in $2007 P<0.02)$ and exercise stress treadmill testing decreased $49 \%$ (471 in 2004 vs. 241 in $2007 P<0.02$ ). Over the same period, there were no significant changes in measures of practice volume (office and hospital) or the annual incidence of PCI (405 cases in 2004 vs. 326 cases in 2007) but a higher percentage of patients with significant disease undergoing PCI $19 \%$ in 2004 vs. $29 \%$ in $2007 P<0.01$. Implementation of CCTA resulted in a significant decrease in ICA and a corresponding significant increase in the percentage of ICA cases requiring PCI, indicating that CCTA resulted in more accurate referral for ICA. The reduction in unnecessary ICA is associated with avoidance of potential morbidity and mortality associated with invasive diagnostic testing, reduction of downstream SPECT MPI and TME as well as substantial savings in health care dollars.

Keywords Coronary computed tomographic angiography · Cardiac computed tomographic angiography · Multi-slice computed tomography · Multi-detector computed tomography . 
Myocardial perfusion imaging $\cdot$ Single-photon emission computed tomography $\cdot$ Exercise treadmill testing - Exercise echocardiography . Downstream utilization - Cardiology practice . Coronary artery disease - Invasive coronary angiography $\cdot$ Percutaneous coronary intervention

$\begin{array}{ll}\text { Abbreviations and acronyms } \\ \text { CAD } & \text { Coronary artery disease } \\ \text { CCS } & \text { Coronary calcium score } \\ \text { CCTA } & \begin{array}{l}\text { Coronary computed tomographic } \\ \text { angiography }\end{array} \\ \text { CLCD } & \text { California local coverage determination } \\ \text { CT } & \text { Computed tomography } \\ \text { ECG } & \text { Electrocardiogram } \\ \text { ICA } & \text { Invasive coronary angiography } \\ \text { MDCT } & \text { Multidetector computed tomography } \\ \text { MPI } & \text { Myocardial perfusion imaging } \\ \text { PCI } & \text { Percutaneous coronary intervention } \\ \text { SBE } & \text { Supine bicycle exercise echocardiography } \\ \text { SPECT } & \text { Single proton emission computed } \\ & \text { tomography } \\ \text { TME } & \text { Treadmill exercise testing }\end{array}$

\section{Introduction}

Cardiac risk stratification and identification of patients requiring intensive medical therapy versus those who might benefit from revascularization has in part relied on myocardial perfusion imaging [1, 2]. The substantial morbidity, mortality, and economic costs associated with coronary artery disease (CAD) have stimulated the development and adoption of alternative methods. Even though several prospective studies have concluded that MPI for patients without limiting symptoms can serve as a gatekeeper to ICA [3-7] there is an opportunity for more specific and sensitive referral for invasive angiography.

Noninvasive coronary computed tomographic angiography (CCTA), which visualizes coronary artery stenosis directly (rather than ischemia), has been proposed as an alternative noninvasive imaging modality for evaluation of patents with known or suspected CAD [8]. Studies comparing 64-slice CCTA to invasive coronary angiography (ICA) as the gold standard have reported a high (>95\%) negative predictive value (i.e., ability to exclude the presence of coronary atherosclerosis) and high diagnostic sensitivity for identifying stenosis in the proximal and mid segments $(>1.5 \mathrm{~mm}$ in diameter) of the main coronary arteries [9-15]. Despite the potential of CCTA in the evaluation of patients, great concern has been expressed regarding the possibility that CCTA will result in increased testing or layering of tests [16].

Since there is little data regarding the impact of CCTA on subsequent downstream test we assessed the effect of CCTA on utilization of other non invasive tests in a "real world setting", a 17 member cardiology group (Cardiovascular Medical Group of Southern California, Beverly Hills California). We conducted a retrospective review of practice volume (new patient and office consultations, follow-up office visits, hospital admissions and consultations, follow-up hospital visits), and the number of noninvasive (ECG, TME, SBE, SPEC MPI, CCS, CCTA) and invasive procedures (ICA, PCI) performed annually for the first 2 years in which CCTA was available (2006-2007) and the two prior years (20042005).

\section{Methods}

Patients and data collection

To determine the number of non-invasive and invasive procedures performed during the period from January 1, 2004 through December 31, 2007, billing codes for non-invasive (CCTA, MPI, SBE, TME) and invasive (ICA, PCI) procedures were identified and used to query the practice management system (Megawest ${ }^{\circledR}$ ). Additionally, the practice management system was queried for practice demographics each year (new patient and office consultations, follow-up office visits, hospital admissions and consultations, follow up hospital visits).

\section{Multidetector computed tomography}

CCTA became available in the practice in late 2005 with the first full year of operation in 2006. CCTA generally was performed in patients determined to be at intermediate risk by the referring cardiologist and with indications as outlined in the California 
Medicare Local Coverage Determination for Cardiac CT [16]. Only patients without contraindication to iodinated contrast agents were tested. The use of CCTA by individual physicians, as the first test compared to MPI-SPEC varied among physicians and over the years with a tendency to broader use and more frequent use as the first test in later years.

Data acquisition was performed using a 64-slice multidetector computed tomography (MDCT) (LightSpeed ${ }^{\circledR}$ VCT 64-Slice scanner, GE Medical systems). To avoid motion artifacts caused by elevated heart rate, prior to the procedure patients routinely received 50-100 mg metoprolol orally several hours prior to the procedure, followed by up to $100 \mathrm{mg}$ of intravenous metoprolol as needed to achieve HR $<60 \mathrm{bpm}$. All patients had oral hydration before and after the study. Nitroglycerine spray $(0.4 \mathrm{mcg})$ was administered just before the test. After a noncontrast scan using $2.5 \mathrm{~mm}$ thick slices to measure the CCS, 60-100 mg intravenous contrast (Visipaque ${ }^{\circledR}$ (iodixanol) or Omnipaque ${ }^{\circledR}$ (iohexol), GE Healthcare) was infused. Triggered by aortic contrast aorta opacification, CT acquisition for CCTA was performed during a breath-hold. Detector collimation was set at 64 channels $\times 0.625 \mathrm{~mm} /$ slice, gantry rotation speed at $375 \mathrm{~ms}$ per rotation, and tube voltage $100-140 \mathrm{kV}$ (depending on the patient's body weight) at a current of 350-750 mA with retrospective helical reconstruction and dose modulation or prospective scanning. Image data sets were analyzed using multiplanar reconstruction, volume rendering, and vessel analysis software packages (AW 4.3 and 4.4, GE Medical Systems); this technology allowed reconstructed slice thickness of approximately $0.6 \mathrm{~mm}$.

The CCS was assessed using semi-atomically (SmartScore 3, GE Medical Systems. A calcified lesion was defined as the presence of $\geq 1$ lesion of $\geq 3$ pixels with a peak Hounsfield unit (HU) density of $>130$. The Agaston score for determination of the CCS was calculated as: area of calcification $\times$ peak density [17].

All CCTA angiograms were evaluated by readers meeting level III experience as defined by ACC/AHA criteria [18] and reported according to SCCT criteria [19]. Study quality was determined on the basis of motion artifact and contrast-to-noise ratio. After qualitative assessment, a lesion was evaluated as normal, $0-25,26-50,51-75,>75 \%$ and absence of contrast opacification of the coronary artery lumen was considered to represent total coronary occlusion or subtotal occlusion. Non calcified plaque burden was evaluated as none, mild, moderate or severe and the CCS score was reported for each CCTA. The attending Cardiologist independently decided on downstream testing or testing prior to CCTA.

Invasive coronary angiography

ICA was performed by the Judkins' technique. Standard projections were obtained after intracoronary injection of Visipaque ${ }^{\circledR}$ (iodixanol) or Omnipaque $^{\circledR}$ (iohexol) (GE Healthcare). Decisions for percutaneous coronary intervention were made independently by the interventional cardiologist who reviewed all non invasive testing information, the clinical history before proceeding with PCI.

Data analysis

Annual utilization and practice demographics were summarized in an Excel (Microsoft) spreadsheet. For each parameter, a linear regression analysis was performed to assess the statistical significance of the trend over the 4-year period. Bar charts were constructed to graphically represent utilization of both non-invasive and invasive diagnostic procedures for all 4 years.

\section{Results}

Annual practice demographics and procedure utilization rates for the period from 2004 to 2007 are summarized in Table 1, and annual utilization of noninvasive and invasive procedures is depicted in Figs. 1 and 2. During the study period, there were no significant changes in indicators of practice volume including office and hospital patient visits admissions and consultations. Also the number of ECGs another measure of general office activity did not change significantly.

During 2006, the first full year of availability, 1,405 CCTA studies were performed; in the second full year, the number of CCTA studies decreased (from 1,405 to 945). Increased utilization of CCTA was associated with a significant $49 \%$ decrease in TMT exercise tests (471 in 2004 vs. 241 in 2007, $P=0.023$ ) and significant $19 \%$ reduction in SPEC 
Table 1 Utilization data, 2004-2007 significant

\begin{tabular}{|c|c|c|c|c|c|}
\hline & 2004 & 2005 & 2006 & 2007 & $P$-value \\
\hline \multicolumn{6}{|l|}{ Practice demographics } \\
\hline New patients and office consults & 3,998 & 3,780 & 3,665 & 3,665 & NS \\
\hline Follow-up office visits & 27,857 & 25,837 & 26,384 & 27,401 & NS \\
\hline Hospital admissions and consultations & 3,416 & 2,878 & 2,773 & 3,468 & NS \\
\hline Hospital visits & 18,087 & 15,517 & 13,593 & 16,200 & NS \\
\hline \multicolumn{6}{|l|}{ Non-invasive procedures } \\
\hline ECG & 15,679 & 13,358 & 13,903 & 14,670 & NS \\
\hline TME & 471 & 401 & 272 & 241 & 0.023 \\
\hline SBE & 1,116 & 952 & 1,146 & 1,223 & NS \\
\hline SPECT & 3,223 & 3,139 & 2,810 & 2,614 & 0.021 \\
\hline Calcium score & 0 & 30 & 715 & 1132 & 0.045 \\
\hline CCTA & 0 & 74 & 1405 & 945 & N/A \\
\hline \multicolumn{6}{|l|}{ Invasive procedures } \\
\hline ICA & 2,083 & 1,848 & 1,589 & 1,150 & 0.012 \\
\hline PCI & 405 & 457 & 425 & 326 & NS \\
\hline Stents & 352 & 379 & 386 & 275 & NS \\
\hline PTCA & 53 & 78 & 39 & 51 & NS \\
\hline PCI/ICA (\%) & $19 \%$ & $25 \%$ & $27 \%$ & $28 \%$ & 0.008 \\
\hline
\end{tabular}

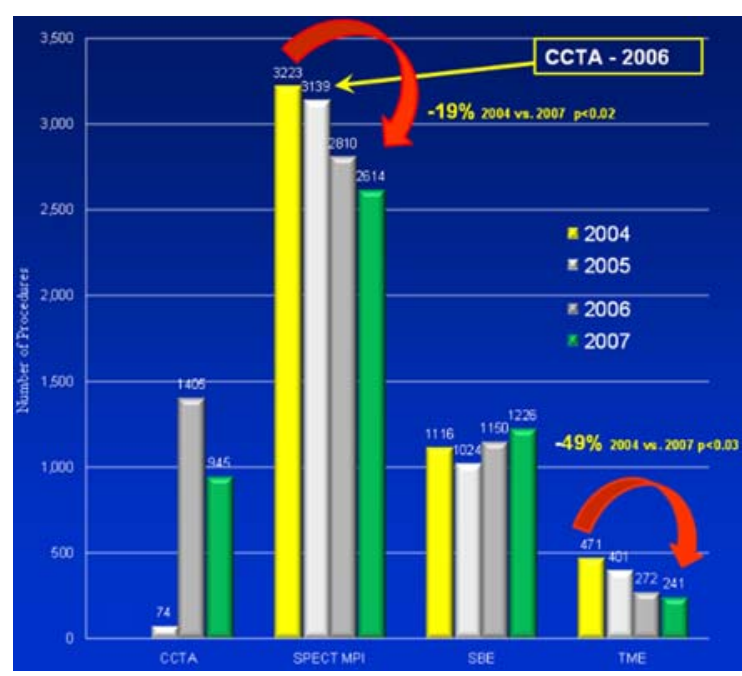

Fig. 1 Utilization of non-invasive diagnostic procedures from 2004 to 2007. Changes in utilization of cardiac testing from 2004 to 2007. CCTA first full year of implementation was in 2006. SPECT MPI utilization fell 19\% and TME fell $49 \%$ between the years 2004 and 2007

MPI (3,223 in 2004 vs. 2,614 in $2007, P=0.021)$, but had no significant impact on SBE with a non significant trend upwards.

Over this time, increased utilization of CCTA was associated with a significant $45 \%$ decrease in ICA procedures $(2,083$ in 2004 vs. 1,150 in 2007 ,

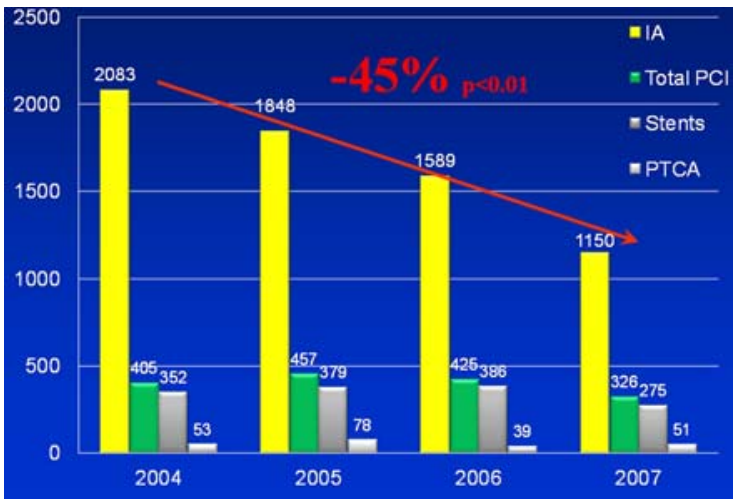

Fig. 2 Utilization of invasive procedures from 2004 to 2007. The number of invasive coronary angiogram fell $45 \%$ between the years 2004 and 2007 following the implementation of CCTA in the year 2006. However, the incidence of PCI remained stable

$P<0.012)$ but had no significant impact on PCI incidence (405 in 2004 vs. 326 in 2007). Implementations of CCTA in the office also was associated with a significant $53 \%$ increase in the proportion of ICA undergoing PCI (19\% in 2004 vs. $29 \%$ in 2007 $P=0.008)$.

Overall procedures, including CCTA, decreased. Comparing all procedures from 2004 to 2007, there were 230 less TMT, 609 less SPECT scans, 933 less 
ICA and 79 less PCI, offset by an increase of 945 CTA. Thus 1,851 less procedures were offset by an increase in 945 CTA procedures. The overall revenue of the practice when considering the addition of CCTA and reduction in other non-invasive testing was within $10 \%$ each year and although lower in later years changes did not reach statistical significance.

\section{Discussion}

Once 64-slice MDCT was implemented, CCTA was rapidly adopted within the practice. During the first full year of availability, 1,405 CCTA procedures were performed. During the second year, fewer CCTA procedures were performed as other community CTs became available and as cardiologists became familiar with indications and utility of CCS testing. Increased reliance on CCS might have played a role in a lower second year volume of CCTA and going forward physicians focused on measurable plaque burden and altered their medical approach. We have previously reported in this cohort that the findings of calcified and non-calcified plaque on Cardiac CT lead to a change in medical strategy for CAD with aggressive reduction of LDLs, this despite near normal LDL values at baseline [20, 21].

The adoption of CCTA was also associated with a significant reduction in SPECT MPI, suggesting that CCTA replaced SPECT MPI to some extent. The reduction in SPECT MPI may be explained by a shift in diagnostic paradigm in which CCTA was performed as a first line test instead of SPECT MPI for evaluation of patients with intermediate pretest risk of $\mathrm{CAD}$, consistent with current appropriateness criteria $[8,18]$. Further, the strong negative predictability of CCTA would support a decreased need for downstream SPECT MPI [10, 22]. Also, the number of stress echocardiograms performed in the last 2 years of the study is greater than the first 2 years, most likely reflecting some substitution of SPECT MPI to stress echocardiography, perhaps due to the desire to avoid a second test utilization radiation.

The reduced number of patients referred for invasive coronary angiography and SPECT MPI was partially offset by the number of patients getting CCTA, Calcium scores. However, this resulted in a substitution of very high cost invasive coronary angiography by lower cost office based testing. Since diagnostic cardiac catheterization is associated with severe adverse events in $0.7-1.5 \%$ of patients and associated deaths in $0.07 \%$ the avoidance of unnecessary cardiac catheterization in subjects at relatively low risk of cardiac events is clinically significant and with substantial cost savings [23-25].

Others have predicted or have estimated that the potential reductions in myocardial perfusion imaging and invasive coronary angiography might be considerable in the setting of the utilization of CCTA as the first test for the intermediate risk patient or the patient with acute coronary syndrome [26-29]. Such estimates suggest reductions in excess of 74\%. [26]. However, this is the first report in a "real world" uncontrolled setting which documents dramatic reductions in ICA and simultaneous reduced downstream testing of SPECT MPI and TME. Even more appropriate and cost efficient testing might be achievable by only considering patients for provocative testing who have failed medical management and or have suspicious narrowing's on CCTA that require invasive coronary for clarification or intervention.

In this practice, implementation of CCTA was associated with a significant $45 \%$ decrease in ICA over the study period (from 2,083 procedures in 2004 to 1,150 in $2007, P=0.012$ ) but had no significant impact on the number of percutaneous revascularization procedures performed. As a result, implementation of CCTA was associated with a significant 53\% increase $(P=0.008)$ in the proportion of ICA studies showing significant angiographic narrowing's resulting in the need for percutaneous coronary intervention. This implies that there was more accurate detection of disease that ultimately underwent PCI with fewer patients with normal or non occlusive disease undergoing invasive coronary angiography. Following publication of the COURAGE trial in the spring of 2007 [30] this practice experienced a trend toward reduced incidence of PCI (425 in 2006 vs. 326 in 2007) which did not achieve statistical significance. Further evaluation will need to assess utilization rates over the next few years to determine whether there is a significant lasting change in the intervention strategy and resulting impact on ICA and PCI utilization. Finally, this study performed in a private practice cardiology group, parallels a university medical center study which showed a $30 \%$ decrease in non-invasive imaging after introduction of CCTA [31]. However, in that study there was a 
reported growth of the invasive angiography practice and also decisions may have been controlled by multiple individuals in an academic setting thus confounding the ability to implement and measure an opportunity to reduce the incidence of invasive angiography.

The limitations of our study need consideration: (1) The trends in noninvasive and invasive procedures reported in this study should be viewed with some caution, given the short observation period (2 years before and 2 years after installation of the 64-slice MDCT) and the potential confounding factors of an uncontrolled retrospective study in the setting of concerns about late stent stenosis [32] improved medical management $[33,34]$ and modest trends towards general reduction in both invasive angiography and PCI in similar practices of approximately 10\% (MedAxiom, Neptune Beach Floridaprivate communication). The utilization of angiography is dynamic and under many influences and therefore CCTA may not solely account for the reduction found in this study. (2) The effects of availability of the calcium score on downstream testing independent of CCTA cannot be determined from this study. (However, identification of non calcified plaque found on CCTA enhanced lipid management [20]). (3) The findings of a normal or non occlusive CCTA may have lead to fewer MPISPECT testing and invasive coronary angiography downstream over the entire 4 years once significant occlusive CAD was excluded. Thus, the ability to analyze each year effects sequential is impaired.

\section{Conclusions}

Despite these limitations, the dramatic reduction in ICA observed obviates the fear that the anatomic knowledge of asymptomatic coronary narrowing's would lead to increased invasive angiography or more interventions. To the contrary, the introduction of non-invasive CT angiography was associated with a $45 \%$ decrease in invasive coronary angiography particularly among those not requiring PCI. In this "real world" uncontrolled setting there was also a decrease (19\%) in nuclear perfusion exams and the opportunity for even greater reductions in noninvasive testing. Finally in view of demonstrated reduction of reduction exposure of $90 \%$ [35], CCTA with its strong negative predictability, simultaneous capacity not to miss serious disease and ability to discern those who might benefit from medical versus an invasive strategy is an attractive choice as the first test for the intermediate risk patient. Prospective multicenter control trials are warranted to evaluate the opportunity to reduce the rate of overall cardiac imaging procedures, to redefine the utilization and choice of non invasive testing, to find the best pathway to avoid redundant layering of testing and to be sure the right patient gets referred for invasive coronary angiography.

Disclosures GE Healthcare provided support to $S^{2}$ Statistical Solutions, Inc. (Cincinnati, Ohio) for an independent statistician (C. Gunnarsson) to perform statistical analyses of the database. GE Healthcare had no other role in the performance of the study or manuscript preparation. No one from GE Healthcare or any other entity has seen or had any control over the data in this manuscript. No other potential conflicts of interest are present. The principal investigator had full access to the results and the manuscript was written independently of the sponsor.

Open Access This article is distributed under the terms of the Creative Commons Attribution Noncommercial License which permits any noncommercial use, distribution, and reproduction in any medium, provided the original author(s) and source are credited.

\section{References}

1. Shaw LE, Iskandrian AE (2000) Prognostic value of stress gated SPECT in patients with known or suspected coronary artery disease. J Nucl Cardio 1:171-185

2. Berman DS, Germano G, Shaw L (1999) The role of nuclear cardiology in clinical decision making. Semin Nucl Med 29:280-297

3. Hachamovitch R, Berman DS, Shaw LJ, Kiat H, Cohen I, Cabico JA, Friedman J, Diamond GA (1998) Incremental prognostic value of myocardial perfusion single photon emission computed tomography for the prediction of cardiac death: differential stratification for risk of cardiac death and myocardial infarction. Circulation 97:535-543

4. Hachamovitch R, Hayes SW, Friedman JD, Cohen I, Berman DS (2000) Comparison of the short-term survival benefit associated with revascularization compared with medical therapy in patients with no prior coronary artery disease undergoing stress myocardial perfusion single photon emission computed tomography. Circulation 41: $1125-1133$

5. Høilund-Carlsen PF, Johansen A, Christensen HW, Vach W, Møldrup M, Bartram P, Veje A, Haghfelt T (2006) Potential impact of myocardial perfusion scintigraphy as gatekeeper for invasive examination and treatment in 
patients with stable angina pectoris: observational study without post-test referral bias. Eur Heart J 27:29-34

6. Shaw LJ, Hachamovitch R, Berman DS, Marwick TH, Lauer MS, Heller GV, Iskandrian AE, Kesler KL, Travin MI, Lewin HC, Hendel RC, Borges-Neto S, Miller DD (1999) The economic consequences of available diagnostic and prognostic strategies for the evaluation of stable angina patients: an observational assessment of the value of precatheterization ischemia. J Am Coll Cardiol 33:661-669

7. Underwood SR, Godman B, Salyani, Ogle JR, Ell PJ (1999) Economics of myocardial perfusion scintigraphy in Europe-the EMPIRE study. Eur Heart J 20:157-166

8. Budoff MJ, Achenbach S, Blumenthal RS, Carr JJ, Goldin JG, Greenland P, Guerci AD, Lima JAC, Rader DJ, Rubin GD, Shaw LJ, Wiegers SE (2006) Assessment of coronary artery disease by cardiac computed tomography: a scientific statement from the American heart association committee on cardiovascular imaging and intervention, council on cardiovascular radiology and intervention, and committee on cardiac imaging, council on clinical cardiology. Circulation 114:1761-1791

9. Bedi HS, Gill JA, Bakshi S (2008) Can we perform coronary artery bypass grafting on the basis of computed tomographic angiography alone? A comparison with conventional coronary angiography. Eur J Cardiothorac Sur 33:633-638

10. Budoff MJ, Dowe D, Jollis JG, Gitter M, Sutherland J, Halamert E, Scherer M, Bellinger R, Martin A, Benton R, Delago A, Min JK (2008) Diagnostic performance of 64detector row coronary computed tomographic angiography of individuals undergoing invasive coronary prospective multicenter accuracy (assessment by coronary computed individuals without known coronary artery disease: results from the tomographic angiography for evaluation of coronary artery stenosis in angiography) trial. J Am Coll Cardiol 52(21):1724-1732

11. Heuschmid M, Burgstahler C, Reimann A, Brodoefel H, Mysal I, Haeberle E, Tsiflikas I, Claussen CD, Kopp AF, Schroeder S (2007) Usefulness of noninvasive coronary imaging using dual-source computed tomography in an unselected population with high prevalence of coronary artery disease. Am J Cardiol 100:587-592

12. Leber AW, Knez A, von Ziegler F, Becker A, Nikolaou K, Paul S, Wintersperger B, Reiser M, Becker CR, Steinbeck G, Boekstegers P (2005) Quantification of obstructive and nonobstructive coronary lesions by 64-slice computed tomography. A comparative study with qualitative coronary angiography and intravascular ultrasound. J Am Coll Cardiol 46:147-154

13. Leschka S, Alkadhi H, Plass A, Desbiolles L, Grünenfelder J, Marincek B, Wildermuth S (2005) Accuracy of MSCT coronary angiography with 64-slice technology: first experience. Eur Heart J 26:1482-1487

14. Mollet NR, Cademartiri F, van Mieghem CAG, Runza G, McFadden EP, Baks T, Serruys PW, Krestin GP, de Feyter PJ (2005) High-resolution spiral computed tomography coronary angiography in patients referred for diagnostic conventional coronary angiography. Circulation 112:23182323

15. Schuijf JD, Wijns W, Jukema JW, Atsma DE, de Roos A, Lamb HJ, Stokkel MP, Dibbets-Schneider P, Decramer I, De
Bondt P, van der Wall EE, Vanhoenacker PK, Bax JJ (2006) Relationship between noninvasive coronary angiography with multi-slice computed tomography and myocardial perfusion imaging. J Am Coll Cardiol 48:2508-2514

16. Center for Medicare and Medicaid Services (2008) LCD for multislice or multidetecter computed tomography angiography of the heart and great vessels (L22517-retired) Center for Medicare and Medicaid Services : California (https://www.codemap.com/content.cfm?id=7280\&sid=28\& lcd=22517). Accessed Nov 15, 2009

17. Agatston AS, Janowitz WR, Hildner FJ, Zusmer NR, Viamonte M Jr, Detrano R (1990) Quantification of coronary artery calcium using ultrafast computed tomography. J Am Coll Cardiol 15:827-832

18. Hendel RC, Patel MR, Kramer CM, Poon M, Hendel RC, Carr JC, Gerstad NA, Gillam LD, Hodgson JM, Kim RJ, Kramer CM, Lesser JR, Martin ET, Messer JV, Redberg RF, Rubin GD, Rumsfeld JS, Taylor AJ, Weigold WG, Woodard PK, Brindis RG, Hendel RC, Douglas PS, Peterson ED, Wolk MJ, Allen JM, Patel MR (2006) ACCF/ ACR/SCCT/SCMR/ASNC/NASCI/SCAI/SIR 2006 appropriateness criteria for cardiac computed tomography and cardiac magnetic resonance imaging. J Am Coll Cardiol 48:1475-1497

19. Raff GL, Aiden A, Achenbach S, Berman DS, Boxt LM, Budoff MJ, Cheng V, DeFrance T, Hellinger JC, Karlsberg RP (2009) SCCT guidelines for the interpretation and reporting of coronary computed tomographic angiography. J Cardiovasc Comput Tomogr 3(2):122-136

20. Karlsberg RP, Budoff MJ, Berman DS, Thomson LEJ, Friedman JD (2008) Integrated coronary CTA in an office based cardiology practice reduces myocardial perfusion imaging and exercise treadmill testing in the setting of increased identification of cad, stable office economics and more aggressive lipid management. J Am Coll Cardiol 51:A139

21. Karlsberg RP, Budoff MJ, Thomson LEJ, Friedman JD, Berman DS (2009) Integrated coronary computed tomographic angiography in an office-based cardiology practice. Rev Cardiovasc Med 10(4):1-8

22. Min JK, Shaw LJ, Devereux RB, Okin PM, Weinsaft JW, Russo DJ, Lippolis NJ, Berman DS, Callister TQ (2007) Prognostic value of multidetector coronary computed tomographic angiography for prediction of all-cause mortality. J Am Coll Cardiol 50:1161-1170

23. Fine JJ, Hopkins CB, Hall PA, Delphia RE, Attebery TW, Newton F (2004) Noninvasive coronary angiography: agreement of multi-slice spiral computed tomography and selective catheter angiography. Int $\mathbf{J}$ Cardiovasc Imaging 20:549-552

24. Tavris DR, Gallauresi BA, Lin B, Rich SE, Shaw RE, Weintraub WS, Brindis RG, Hewitt K (2004) Risk of local adverse events following cardiac catheterization by hemostasis device use and gender. J Invas Cardiol 16:459-464

25. Noto TJ Jr, Johnson LW, Krone R, Weaver WF, Clark DA, Kramer JR Jr, Vetrovec GW (1991) Cardiac catheterization 1990: a report of the Registry of the Society for Cardiac Angiography and Intervention (SCA\&I) Cathet Cardiovas Diagn 1991 24:75-83

26. Devine PJ, Villines TC, Sullenberger LE, Anderson DR, Malik AK, Feuerstein IM, Taylor AJ (2008) Real world 
application of coronary computed tomography angiography and its potential effects on downstream resource utilization in evaluating angina. $\mathrm{J}$ Cardiovas Comput Tomogr 2:214-219

27. Budoff MJ, Gopal A, Gul KM, Mao SS, Fischer H, Oudiz R (2008) Prevalence of obstructive coronary artery disease in an outpatient cardiac CT angiography environment. Int J Cardiol 129(1):32-36

28. Gilard M, Le Gal G, Cornilly JC, Vinsonneau U, Joret C, Pennec PY, Mansourati J, Boschat J (2007) Midterm prognosis of patients with suspected coronary artery disease and normal multislice computed tomographic findings: a prospective management outcome study. Arch Intern Med 167:1686-1689

29. Rubinshtein R, Halon DA, Gaspar T, Jaffe R, Goldstein J, Karkabi B, Flugelman MY, Kogan A, Shapira R, Peled N, Lewis BS (2007) Impact of 64-slice cardiac computed tomographic angiography on clinical decision-making in emergency department patients with chest pain of possible myocardial ischemic origin. Am J Cardiol 100:1522-1526

30. Boden WE, O'Roure RA, Teo KK (2007) For the courage trial research group. Optimal medical therapy with or without PCI for stable coronary disease. N Engl J Med 356:1503-1516

31. Auseon AJ, Advani SS, Bush CA, Raman SV (2009) Impact of 64-slice multidetector computed tomography on other diagnostic studies for coronary artery disease. Am J Med 122:387-389

32. Mishkel GJ, Moore AL, Markwell S, Shelton MI (2008) Correlates of late and very late thrombosis of drug eluding stents. Am Heart J 156:141-147

33. Brown WV (2000) Cholesterol lowering in atherosclerosis. Am J Cardiol 86:23-29

34. Jabbour S, Young-Xu Y, Graboys TB, Blatt CM, Goldberg RJ, Bedell SE, Bilchik BZ, Lown B, Ravid S (2004) Long Term outcomes of optimized medical management of outpatients with stable coronary artery disease. Am J Cardiol 93:294-299

35. Gopal A, Mao SS, Karlsberg D, Young E, Waggoner J, Ahmadi N, Pal RS, Leal J, Karlsberg RP, Budoff MJ (2009) Radiation reduction with prospective ECG-triggering acquisition using 64-multidetector computed tomographic angiography. In J Cardiovasc Imaging 25(4):417419 